
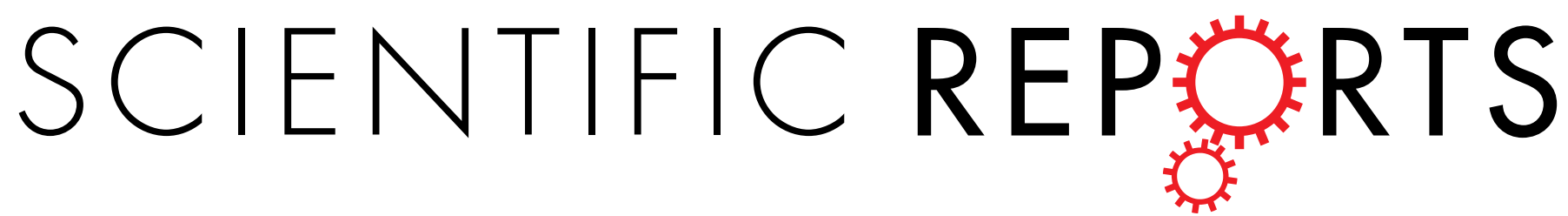

OPEN

\title{
Occurrence and removal of phenolic endocrine disrupting chemicals in the water treatment processes
}

Received: 13 October 2015

Accepted: 19 February 2016

Published: 08 March 2016
Xuemin Lv, Sanhua Xiao, Gang Zhang, Pu Jiang \& Fei Tang

This paper evaluated the occurrence and removal efficiency of four selected phenolic endocrine disrupting chemicals (bisphenol A (BPA), octylphenol (OP), nonylphenol (NP) and diethylstilbestrol (DES)) in two drinking waterworks in Jiangsu province which take source water from Taihu Lake. The recombined yeast estrogen screen (YES) and liquid chromatography tandem mass spectrometry (LCMS/MS) were applied to assess the estrogenicity and detect the estrogens in the samples. The estrogen equivalents (EEOs) ranged from nd (not detected) to $2.96 \mathrm{ng} / \mathrm{L}$, and the estrogenic activities decreased along the processes. Among the 32 samples, DES prevailed in all samples, with concentrations ranging $1.46-12.0 \mathrm{ng} / \mathrm{L}, \mathrm{BPA}, \mathrm{OP}$ and NP were partially detected, with concentrations ranging from nd to $17.73 \mathrm{ng} / \mathrm{L}$, nd to $0.49 \mathrm{ng} / \mathrm{L}$ and $\mathrm{nd}$ to $3.27 \mathrm{ng} / \mathrm{L}$, respectively. DES was found to be the main contributor to the estrogenicity $(99.06 \%)$, followed by NP $(0.62 \%)$, OP $(0.23 \%)$ and BPA $(0.09 \%)$. From the observation of treatment efficiency, the advanced treatment processes presented much higher removal ratio in reducing DES, the biodegradation played an important role in removing BPA, ozonation and pre-oxidation showed an effective removal on all the four estrogens; while the conventional ones can also reduce all the four estrogens.

Endocrine disrupting compounds (EDCs) has been reported for over 80 years ${ }^{1}$. They are known as a class of chemicals which have xenobiotic and exogenous origins while mimicking or inhibiting the natural actions of the endocrine system in animals and human, such as synthesis, secretion, transport, and binding. They maintain the homeostasis, reproduction, metabolism, development, and/or behavior of living species and include diverse groups of heterogeneous contaminants (alkylphenols, polychlorinated biphenyls, selected pesticides, steroid sex hormones, phthalates etc. $)^{2-4}$.

The presence of EDCs in the aquatic systems (wastewaters, drinking water and underground water) is considered as a major environmental issue ${ }^{5-9}$. Phenolic estrogens are commonly included in the reported EDCs in the wastewater and drinking water, such as bisphenol-A (BPA), diethylstilbestrol (DES), octylphenol (OP), nonylphenol (NP) and corresponding ethoxylates ${ }^{10-12}$. These compounds has become ubiquitous in the environment because of their presence in a multitude of products including food and beverage packaging, surfactants, flame retardants, adhesives, building materials, electronic components, paper coatings and pharmaceutical personal care products (PPCPs). They can cause adverse effects to human bodies ${ }^{12-15}$. Furthermore, the increasing incidences of cancer and decreasing reproductive fitness in humans are thought to be caused by exposure to estrogenic compounds, including phenolic compounds, especially via drinking water ${ }^{16,17}$. The occurrence and distribution of these phenolic EDCs have been widely reported in drinking water ${ }^{18-20}$, but limited studies focus on the removal of these chemicals during the drinking water treatment processes ${ }^{21,22}$, especially the situations in China.

As one of the most important drinking water sources, Taihu Lake supplies more than $50 \%$ of the population in Jiangsu province. Water quality in this area is attracting great environmental, health and safety concern. The occurrence of contaminants like EDCs has been reported as an increasing amount of pollutants that has been discharged into the lake directly and indirectly with the development of industry and agriculture ${ }^{23}$. However, few studies have comprehensively dealt with the occurrence and removal of the phenolic EDCs during the water treatment processes which take source water from Taihu Lake.

Department of Environmental Microbiology, Institute of Environmental Medicine, MOE Key Lab of Environment and Health, School of Public Health, Tongji Medical College, Huazhong University of Science and Technology, Wuhan 430030, P.R. China. Correspondence and requests for materials should be addressed to F.T. (email: feitang@mails. tjmu.edu.cn) 
Conventional water treatment processes (coagulation, sedimentation, sand filtration, and chlorination) have been used for decades, and with the pollution becoming more serious and the purpose of improving drinking water quality, advanced water treatment processes (ozonation, activated carbon and ultra-membrane filtration) have been applied in a waterworks (Taihu Lake source) five years ago. Therefore, it is important to evaluate the concentrations and fate of phenolic EDCs in the waterworks since the related studies on these compounds in drinking water systems are limited, and the efficiencies of advanced processes need to be evaluated.

The instrumental monitoring like liquid chromatography tandem mass spectrometry (LC-MS/MS) can provide qualitative and quantitative information about the environmental contaminants in the water samples, while bioassays can provide measures of the cumulative effects of chemicals that exhibit the same mode of toxic action and thus concentration additive effects. So bioassays are usually used as a complement to instrumental analyses in toxicity identification evaluation schemes to address complex environmental issues ${ }^{24}$. Therefore, in this paper, LC-MS/MS was applied to detect the four selected EDCs (nonylphenol, octylphenol, bisphenol A and diethylstilbestrol) and the in vitro bioassay (recombined yeast estrogen screen, YES) was employed to assess the estrogenic activities at the same time.

Thus the objectives of this paper were to (a) determine the occurrence of the phenolic EDCs in two waterworks that both take source water from Taihu Lake, (b) to discuss the removal efficiencies of the target phenols in the conventional water treatment processes and the advanced treatment processes, (c) to find out the main contributor to the estrogenicity of the four target phenols.

\section{Methods}

Reagents and chemicals. Chemicals used in the YES and standard substances in the chemical analysis were purchased from Sigma-Aldrich Chemical Co. (St. Louis, MO USA): Chlorophenol Red- $\beta$-D galactopyranoside (CPRG), 17 $\beta$-estradiol (E2), nonylphenol (NP), octylphenol (OP), bisphenol A (BPA), bisphenol A-d $\mathrm{d}_{16}$ and diethylstilbestrol (DES). All reagents of HPLC grade used for sample processing and analysis (methanol, dichloromethane, n-hexane and acetone) were obtained from J.T.Baker Avantor Co. (Center Valley, PA, USA). Glass fiber filters (GF/F, pore size $0.7 \mu \mathrm{m}$ ) were obtained from Whatman (Maidstone, $\mathrm{UK}$ ) and prebaked at $450^{\circ} \mathrm{C}$ for $4 \mathrm{~h}$ prior to use. Deionized organic-free water was obtained from a Milli-Q water purification system from Millipore (Bedford, USA). The solid-phase extraction sorbent Sep-Pak C18 vac cartridge (1000 mg, $6 \mathrm{cc}$ ) was supplied by Waters Co. (Milford, MA, USA). Stock solutions of the four phenols were prepared in methanol at $1 \mu \mathrm{g} / \mu \mathrm{L}$ and stored at $-20^{\circ} \mathrm{C}$ for later use; the appropriate working standard solutions were prepared in methanol and stored in amber glass bottles at $4^{\circ} \mathrm{C}$.

Sampling and preparation of solid-phase extraction. Influent (raw water) and effluent (of each treatment process) samples were collected from two waterworks (W-A applied advanced water treatment processes and W-B applied the conventional ones). Sampling campaigns were performed in January and March 2014 that were both during the same hydrographic period (dry period). Scholars reported that in the dry period (December to March) the water level was relatively low and the pollution level is relatively high in Taihu lake, and the estrogencity was more intense compared with other periods ${ }^{25}$, so the results can be more representative in reflecting the occurrence and removal of the of the phenols during the different water treatment processes. Additional details regarding these waterworks are given in Table 1 and Fig. 1.

The samples ( $4 \mathrm{~L}$ each) were collected in amber glass bottles, and filtered through prebaked glass fiber filters to avoid extraction cartridges clogging ${ }^{11}$. The solid phase extractions were performed on the Visiprep ${ }^{\text {TM }}$ SPE Vacuum Manifold DL, for 24 samples from Supelco (Bellefonte, PA, USA). The SPE C18 cartridges, prior to extraction were conditioned with $5 \mathrm{~mL}$ methanol and $5 \mathrm{~mL}$ deionized water. Water samples were passed through the cartridges at a flow rate of $5 \mathrm{~mL} / \mathrm{min}$ under vacuum. After dried under vacuum for $1 \mathrm{~h}$, the target compounds were eluted with $2 \mathrm{~mL}$ methanol, followed by $2 \mathrm{~mL}$ dichloromethane and $2 \mathrm{~mL} \mathrm{n}$-hexane. Then the extracts were dried under a gentle nitrogen stream at $45^{\circ} \mathrm{C}$. For the bioassay (YES), these extracts were dissolved in the anhydrous ethanol to make $0.1 \mathrm{~mL}$ solutions presented for $250 \mathrm{~mL}$ water sample extracts,viz., the concentration factor is 2500; for chemical analysis (LC-MS/MS) the extracts were dissolved in methanol to make 2000 fold concentration. Each final extract was then filtered through a $0.22 \mu \mathrm{m}$ membrane filter into a $2 \mathrm{~mL}$ sealed amber glass vial. The vials were kept at $-20^{\circ} \mathrm{C}$ for later analysis. Blank columns were extracted and treated in the same way as described above.

Yeast estrogen screen (YES) bioassay. The recombinant yeast estrogen screen was carried out according to the protocols detailed by Routledag and Sumpter ${ }^{26}$ using a slightly modified version of procedure described by Rastal et al. ${ }^{27}$. Briefly, the recombinant yeast cells were stably transfected with the gene of the human estrogen receptor (hER) and containing expression plasmids carrying strong promoter sequences and the lac- $\mathrm{Z}$ $(\beta$-galactosidase) reporter gene. Using appropriate growth media, the recombinant yeast cells express hER in a form capable of binding to estrogen response elements (ERE) situated within a promoter sequence on the plasmid. Following the binding of a suitable agonist, the agonist-hER complex interacts with various transcription factors, binds to the ERE and initiates a cascade of events which results in the expression of the lac- $\mathrm{Z}$ reporter gene and the secretion of $\beta$-galactosidase into the assay medium.

The briefly assay procedure: three $100 \mu \mathrm{L}$ extracts representing $250 \mathrm{~mL}$ water sample were serially diluted along alternate rows of a 96 well microtitre plate. A $17 \beta$-estradiol (E2) positive control was added to a separate row and serially diluted to give a final concentration range of $1.00 \times 10^{-8}$ to $4.80 \times 10^{-12} \mathrm{~mol} / \mathrm{L}$. $50 \mathrm{~mL}$ of assay medium containing $500 \mu \mathrm{L}$ of a $1.65 \times 10^{-2} \mathrm{~mol} / \mathrm{L}$ aqueous solution of the chromogenic substrate Chlorophenol-Red- $\beta$-D-galactopyranoside $(\mathrm{CPRG})$ and $4.0 \times 10^{7} / \mathrm{L}$ recombinant yeast cells were then prepared and $200 \mu \mathrm{L}$ transferred to each well. The plates were sealed and incubated at $32^{\circ} \mathrm{C}$ for $72 \mathrm{~h}$. Estrogenic potential 


\begin{tabular}{|c|c|c|c|}
\hline Waterworks & Capacity $^{\mathrm{a}}$ & Treatment Process & Additional Information $^{\mathrm{a}}$ \\
\hline \multirow[t]{20}{*}{ W-A } & 1.0 Million ton & Influent (source) & Raw Water From Taihu Lake \\
\hline & & Pre-Oxidation & Ozonation: $0.6 \mathrm{mg} / \mathrm{L}$ \\
\hline & & & Gas Water Ratio: 0.6-0.8: 1 \\
\hline & & & Contact Time: 10 minutes \\
\hline & & Biodegradation & Biological Aerated Filter \\
\hline & & & Working Depth $=2.0 \mathrm{~m}$ \\
\hline & & & Gas Water Ratio: 0.6-0.8: 1 \\
\hline & & Chlorination & Residual Chlorine $0.05 \mathrm{mg} / \mathrm{L}$ \\
\hline & & Influent & Pipeline length: $21 \mathrm{~km}$ \\
\hline & & & Pipeline Retention Time: 6-7h \\
\hline & & Coagulation and & Aluminium Oxide: $30 \mathrm{mg} / \mathrm{L}$ \\
\hline & & Sedimentation & Contact Time: $3-4 \mathrm{~h}$ \\
\hline & & Sand Filtration & $\begin{array}{c}\text { Quartz Sand: Pore Size } 0.75 \mathrm{~mm} \\
\mathrm{H}=70 \mathrm{~cm}\end{array}$ \\
\hline & & & Flow Rate: $5 \sim 6 \mathrm{~m} / \mathrm{h}$ \\
\hline & & Ozonation & Ozonation: $0.8 \mathrm{mg} / \mathrm{L}$ \\
\hline & & & Contact Time: $10-15 \mathrm{~min}$ \\
\hline & & Activated Carbon filtration & $\begin{array}{c}\text { Granular Activated Carbon: } \\
d=1.5 \mathrm{~mm} ; H=2.1 \mathrm{~m} \\
S=0.5 \times 0.5 \mathrm{~m}\end{array}$ \\
\hline & & Membrane Filtration & $\begin{array}{c}\text { Polyvinylidene Fluoride(PVDF) } \\
\text { Member: } 0.45 \mu \mathrm{m}\end{array}$ \\
\hline & & Finished Water & Residual Chlorine $0.8 \mathrm{mg} / \mathrm{L}$ \\
\hline & & & Retention Time $3 \mathrm{~h}$ \\
\hline \multirow[t]{9}{*}{ W-B } & 0.5 Million ton & Influent(source) & Raw Water From Taihu Lake \\
\hline & & Coagulation and & Aluminium Oxide: $50 \mathrm{mg} / \mathrm{L}$ \\
\hline & & Sedimentation & Contact Time: $2 \mathrm{~h}$ \\
\hline & & Influent & Pipeline length: $38 \mathrm{~km}$ \\
\hline & & & Pipeline Retention Time: $12-15 \mathrm{~h}$ \\
\hline & & Sand Filtration & $\begin{array}{l}\text { Quartz Sand: Pore Size } 0.75 \mathrm{~mm} \\
\mathrm{H}=70 \mathrm{~cm}\end{array}$ \\
\hline & & & Flow Rate: $5 \sim 6 \mathrm{~m} / \mathrm{h}$ \\
\hline & & Finished Water & Residual Chlorine $0.4-0.6 \mathrm{mg} / \mathrm{L}$ \\
\hline & & & Retention Time $2-3 \mathrm{~h}$ \\
\hline
\end{tabular}

Table 1. Details of the waterworks studied. adesign values.

was subsequently determined photometrically at $540 \mathrm{~nm}$ following the conversion of the CPRG from yellow to red by $\beta$-galactosidase secreted into the growth medium in response to the presence of hER agonists in the sample ${ }^{28}$.

Instrumental analysis. The target compounds were analyzed by reversed phase liquid chromatography (Agilent 1260 Infinity, Agilent Technologies, Santa Clara, USA) coupled to a triple quadrupole (QqQ) mass spectrometer (LC-MS/MS 6460, Agilent Technologies, Santa Clara, USA) equipped with an electrospray ionization interface (ESI). The apparatus was composed of a binary pump, autosampler, a degasser and temperature controlled column compartment. The chromatograms were recorded and evaluated by means of the Mass Hunter Workstation Acqusition (Agilent Technologies, Santa Clara, USA). Chromatographic separation was performed on a Zorbax Eclipse Plus C18 column $(100 \mathrm{~mm} \times 2.1 \mathrm{~mm}$ i.d., particle size $3.5 \mu \mathrm{m}$, Agilent Technologies, Santa Clara, USA). Nitrogen was used as the collision and nebulizing gas.

To improve the separation and reduce the analysis time, different experiments were carried out in the gradient mode, the optimal gradient conditions were as follows: Gradient elution consisted of a solution of 30: 70 (v/v) water : methanol started from 0 minute, followed by an increase in methanol to $80 \%$ in 1 minute; held for half a minute; from 1.5 to $2 \mathrm{~min}$ methanol increased to $100 \%$; held for two and a half minutes, finally, from 4.5 to $5 \mathrm{~min}$ methanol decreased back to $70 \%$. The injection volume was $5 \mu \mathrm{L}$ and the flow rate was $0.25 \mathrm{~mL} / \mathrm{min}$. The temperature in the column compartment was set at $40^{\circ} \mathrm{C}$. The analysis was performed using ESI negative, and target analytes were identified and quantified using the multiple-reaction monitoring (MRM) mode. The retention time and MRM parameters are summarized in Table 2.

The estrogen equivalent concentrations measured by the YES assay $\left(\mathrm{EEQs}_{(\mathrm{bio})}\right.$, referring estrogenic activity to the natural estrogen $17 \beta$-estradiol ${ }^{29,30}$ ) were determined as follow: Estrogenic activities of water extracts are expressed as a percentage of the maximum response of the positive control E2 from the same microtiter plate and are plotted to logarithmically transformed equivalents of water sample absolute per well ${ }^{31}$. Also the EEQs were calculated from the chemical analysis of the target compounds based on the theory that all the investigated chemicals target the same receptor ${ }^{32,33}$. The calculated EEQs $\left(\mathrm{EEQs}_{(\mathrm{chem})}\right)$ were expressed as the sum of all estrogenic 


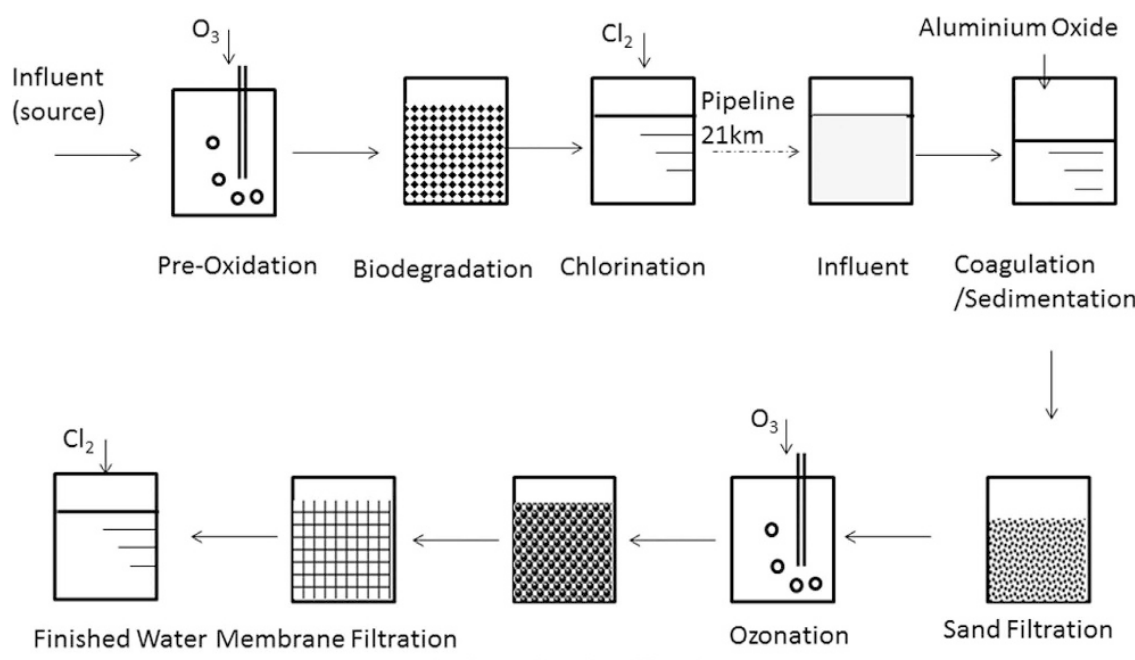

Activated Carbon filtration

W-A

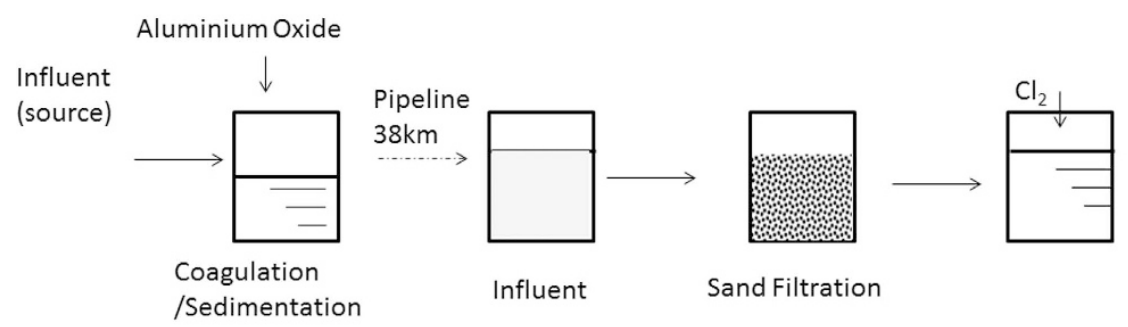

W-B

Figure 1. The water treatment processes of waterworks $A(W-A)$ and waterworks $B(W-B)$.

\begin{tabular}{|c|c|c|c|c|c|c|c|c|}
\hline \multirow[b]{2}{*}{ Compounds } & \multirow[b]{2}{*}{$\mathrm{RT}$ (min) } & \multirow[b]{2}{*}{$\begin{array}{l}\text { Precursor } \\
\operatorname{ion}(\mathbf{m} / \mathbf{z})\end{array}$} & \multicolumn{2}{|c|}{ Compouns parameter } & \multirow[b]{2}{*}{ Product ion } & \multirow[b]{2}{*}{$\operatorname{LOQ}(\mathrm{ng} / \mathrm{L})$} & \multirow[b]{2}{*}{ LOD(ng/L) } & \multirow[b]{2}{*}{ EEF } \\
\hline & & & $\begin{array}{c}\text { Fragmentor } \\
\text { (V) }\end{array}$ & $\begin{array}{c}\text { Collision } \\
\text { energy (V) }\end{array}$ & & & & \\
\hline Bisphenol A (BPA) & 1.92 & 227 & 60 & $20 / 15$ & $212^{*} / 133$ & 11.3 & 3.4 & $3.0 \times 10^{-5}$ \\
\hline Diethylstilbestrol (DES) & 2.40 & 262 & 60 & $30 / 30$ & $237^{\star} / 222$ & 7.7 & 2.3 & $2.1 \times 10^{-2}$ \\
\hline Octylphenol (OP) & 4.39 & 205 & 60 & 15 & 106 & 28.0 & 8.4 & $1.2 \times 10^{-3}$ \\
\hline Nonylphenol (NP) & 4.60 & 219 & 60 & 15 & 106 & 30.7 & 9.2 & $7.0 \times 10^{-4}$ \\
\hline
\end{tabular}

Table 2. Retention time, MRM parameters, LOQs and LODs of target compounds. RT: retention time ${ }^{*}$ quantification ion Source parameter: gas temperature: $300^{\circ} \mathrm{C}$, gas flow: $5 \mathrm{~L} / \mathrm{min}$, Nebulizer: 45 psi, sheath gas temperature: $250^{\circ} \mathrm{C}$, sheath gas flow: $11 \mathrm{~L} / \mathrm{min}$, capillary (negative) $3500 \mathrm{~V}$, nozzle voltage $500 \mathrm{~V}$.

contributions of four compounds by multiplying their estradiol equivalent factors (EEFs) (Table 2) and chemical concentration.

Quality control and quality assurance. All data were subject to strict quality control procedures. The linearities of the method were tested with calibration standards at five concentration levels ranging from 0.01 to $100 \mu \mathrm{g} / \mathrm{L}$. Good linearities were observed for the four target phenolic EDCs, with all the correlation coefficients $\left(r^{2}\right)$ above 0.99 . Limits of quantification (LOQs) (signal-to-noise ratio $=10$ ) and limits of detection (LODs) (signal-to-noise ratio $=3$ ) of the four target compounds are shown in Table 2 . The recovery studies were performed on $4 \mathrm{~L}$ of deionized organic-free water and $4 \mathrm{~L}$ of raw water collected from the Taihu Lake, spiked with known levels (final concentration $100 \mathrm{ng} / \mathrm{L}$ ) of the four compounds respectively (three replicates). Mean recoveries ranged from $87.4 \%$ to $116.9 \%$ for all the targets in the two matrices. The $100 \mathrm{ng} / \mathrm{L}$ mixture of standards was analyzed for six times within a day. The relative standard deviations (RSD) of concentrations for all the targets ranged from $3.19 \%$ to $7.15 \%$ (Table 3), demonstrating the high precision of the analysis methods. In order to ensure the accuracy of the analysis, all samples were replicated three times, and the final concentration averages used.

For the ubiquity of the phenols and to avoid contamination during the sampling and experiment processes, sampling bottles and all glassware used in the experiment were cleaned by washing with detergent, rinsed with 


\begin{tabular}{|l|c|c|c|}
\hline Compounds & $\begin{array}{c}\text { Recovery } \\
(\mathbf{\%})^{\mathbf{a}}\end{array}$ & $\begin{array}{c}\text { Recovery } \\
\mathbf{( \% )}^{\mathbf{b}}\end{array}$ & $\begin{array}{c}\text { RSD } \\
(\mathbf{\%})\end{array}$ \\
\hline Bisphenol A (BPA) & 116.9 & 98.5 & 7.15 \\
\hline Diethylstilbestrol (DES) & 87.4 & 102.1 & 5.36 \\
\hline Octylphenol (OP) & 91.4 & 87.6 & 3.42 \\
\hline Nonylphenol (NP) & 92.3 & 95.3 & 3.19 \\
\hline
\end{tabular}

Table 3. Mean percentage recovery and relative standard deviations (RSD) of target substances. ${ }^{a}$ recovery

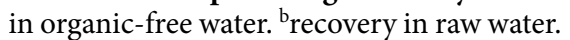

deionized organic-free water, and baked at $450^{\circ} \mathrm{C}$ for at least $4 \mathrm{~h}$. All laboratory materials were either made of glass or Teflon to avoid sample contamination.

\section{Results and Discussion}

Estrogenic activities of the samples in YES assay. All extracts of the water samples were found to induce estrogenic activities at different levels (Table 4). The EEQs $s_{(b i o)}$ values ranged from below LOD to $2.96 \mathrm{ng} / \mathrm{L}$. The estrogenic activities of March samples are a little higher than the samples collected in January, maybe the temperature gets warmer and the activities of the residents around the lake become more frequency lead to these changes. Both the two waterworks showed a good efficiency in reducing the estrogenic activities, for the estrogenic activities decreased along the processes in both waterworks, and the estrogenicites of the finished water are much lower compared to the relative raw water. According to NOEC (no observed effect concentration) of estrogenicity calculated by the researches in the in vitro test ${ }^{34,35}, \mathrm{EEQs}_{(\mathrm{bio})}<0.4 \mathrm{ng} / \mathrm{L}$ was considered as the toxic threshold to human being. Thus in our study, except for the raw water of waterworks B, the estrogenic activities of rest water samples were lower than the threshold. We could also find that the estrogencities of the samples were lower in waterworks $\mathrm{A}$, considering the different water intake points of the two waterworks, water works $\mathrm{B}$ is much nearer to the tributary that run through the residential districts which may bring in more contaminants, that may be the cause to the different estrogenicities.

The in vitro estrogenic activities of the raw waters were almost at the same level compared to home and abroad, where the estrogenic activities of the Taihu Lake ranged from 2.2-8.3 ng/L in China, 0.30-4.50 ng/L of Seine River in France, $0.3-7.0 \mathrm{ng} / \mathrm{L}$ in rivers of Switzerland and $0.7-4.01 \mathrm{ng} / \mathrm{L}$ in Tokyo Bay of Japan ${ }^{36-39}$.

Occurrence of target phenolic compounds in influent and effluent samples. The occurrences of the selected compounds in influent and effluent samples are shown in Table 4 and Fig. 2. Among the 32 samples, DES prevailed in all samples, with concentrations ranging 1.46-12.0 ng/L. BPA, OP and NP were partially detected with concentrations ranging from nd ( $<\mathrm{LOD}$, cannot be detected) to $17.73 \mathrm{ng} / \mathrm{L}$, nd to $0.49 \mathrm{ng} / \mathrm{L}$ and nd to $3.27 \mathrm{ng} / \mathrm{L}$, respectively. In general, concentrations of BPA and DES were much higher than the other two compounds; OP was detected in five samples. Regarding the relative regulations and acts, China government sets limited of BPA in drinking water as below $0.01 \mathrm{mg} / \mathrm{L}^{40}$ and European Commission identified NP as priority hazardous substance ${ }^{41}$; Other EDCs are rarely seen the threshold or limit. These emerging compounds appeared a few decades ago, and the toxicity need to be studied and understand further, the relative regulations also need to be revised as the research being further, there were studies pointed out that BPA could cause adverse effects at very low dose that far below the regulations ${ }^{42}$. Therefore, more attention should be paid to the occurrence of these chemicals.

The variation trend of the four target phenols was shown in Fig. 2. In general, the four chemicals are decreased along the treatment processes, and NP and OP are rarely detected after the raw water being treated. In waterworks A, the concentration of BPA goes up a little after the membrane filtration step; and DES was raised a bit in both the two waterworks in the final treatment processes. The phenomenon was discussed in the later parts.

In the work of Jiang et al., concentrations of OP, NP and BPA detected in Taihu Lake were 3.08-89.52 ng/L; $30.09-280.19 \mathrm{ng} / \mathrm{L}$ and $7.61-710.65 \mathrm{ng} / \mathrm{L}$, respectively ${ }^{20}$. These results are similar to those determined in our study. The concentrations of BPA, DES, OP and NP in the lake water of Wuhan were $20-534 \mathrm{ng} / \mathrm{L}$, nd-9 ng/L, 10-133 ng/L and 260-4042 ng/L, respectively ${ }^{12}$, the observed concentrations of OP, NP and BPA in Wuhan were remarkably higher than our study except for the DES. The different turn out may be due to the different water body and in Wuhan the runoff nearby the lake rarely cover industrial and agricultural activities, the runoff are mostly from the pollutants of human daily activities. All these researches manifested that the drinking water source had been polluted by the phenols at different levels.

Estrogenic activities calculated from the chemical analysis. In order to compare the results of the biological and chemical analysis and to estimate the contribution of target analytes to the overall estrogenic activities of the real samples, chemical estradiol equivalents $\left(\mathrm{EEQs}_{(\mathrm{chem})}\right)$ were determined. Therefore, concentration data obtained by LC-MS/MS analysis were multiplied with the determined relative potencies expressed as EEFs of the compounds in the YES. The EEFs were determined following the principle introduced by Beck ${ }^{31}$, and the EEFs of the four selected chemicals are shown in Table 2. The EEQs $\mathrm{s}_{(\mathrm{chem})}$ are listed in Table 3. From the table, we could find the EEQs vary in the same trend. But there exist some variations, such as the EEQs $s_{(b i o)}$ of source water are much higher than the relative EEQs $s_{(\text {chem })}$ especially the samples of W-B; and for some samples, the EEQs $s_{(b i o)}$ cannot be calculated for the negative reactions in the bioassay while some of the selected compounds can stilled be detected by LC-MS/MS.

The differences between EEQs $s_{(\text {bio })}$ and EEQs $s_{(\text {chem })}$ could have diverse reasons. In general, both the variability of the biological test system and the uncertainty of trace analysis in the $\mathrm{ng} / \mathrm{L}$ range on the equipment could 


\begin{tabular}{|c|c|c|c|c|c|c|c|c|c|c|c|c|c|}
\hline \multirow[b]{2}{*}{ Waterworks } & \multirow[b]{2}{*}{ Treatment Process } & \multicolumn{6}{|c|}{ January 2014} & \multicolumn{6}{|c|}{ March 2014} \\
\hline & & BPA & DES & OP & NP & EEQs(bio) & EEQs(chem) & BPA & DES & OP & NP & EEQs(bio) & EEQs(chem) \\
\hline \multirow[t]{11}{*}{ W-A } & Influent (source) & 3.66 & 7.33 & 0.48 & 0.29 & $0.20 \pm 0.05$ & 0.15 & 2.47 & 12.0 & nd & 1.25 & $0.21 \pm 0.06$ & 0.25 \\
\hline & Pre-Oxidation & 0.72 & 6.74 & nd & nd & nd & 0.14 & 0.85 & 6.68 & nd & nd & $0.29 \pm 0.02$ & 0.14 \\
\hline & Biodegration & 0.6 & 7.21 & nd & nd & $0.08 \pm 0.02$ & 0.15 & nd & 6.31 & nd & nd & $0.23 \pm 0.02$ & 0.13 \\
\hline & Chlorination & 0.32 & 5.41 & nd & nd & nd & 0.11 & 0.25 & 5.69 & nd & nd & $0.28 \pm 0.05$ & 0.12 \\
\hline & Influent & 1.30 & 4.64 & nd & nd & nd & 0.10 & 0.61 & 6.42 & nd & nd & $0.33 \pm 0.05$ & 0.13 \\
\hline & Coagulation and Sedimentation & 0.01 & 5.37 & nd & nd & $0.03 \pm 0.05$ & 0.11 & 0.91 & 5.99 & nd & nd & $0.22 \pm 0.01$ & 0.13 \\
\hline & Sand Filtration & 0.01 & 5.75 & nd & nd & nd & 0.12 & 1.17 & 5.96 & nd & nd & $0.22 \pm 0.01$ & 0.13 \\
\hline & Ozonation & 0.23 & 2.90 & nd & nd & $0.05 \pm 0.04$ & 0.06 & 0.52 & 3.82 & nd & nd & $0.15 \pm 0.01$ & 0.08 \\
\hline & Activated Carbon filtration & 0.41 & 1.91 & nd & nd & $0.08 \pm 0.02$ & 0.04 & 2.83 & 2.04 & nd & nd & nd & 0.04 \\
\hline & Membrane Filtration & 0.47 & 1.76 & nd & nd & $0.07 \pm 0.01$ & 0.04 & 7.37 & 1.46 & nd & nd & nd & 0.03 \\
\hline & Finished Water & 1.22 & 1.92 & nd & nd & $0.07 \pm 0.01$ & 0.04 & nd & 3.30 & nd & nd & $0.09 \pm 0.09$ & 0.07 \\
\hline \multirow[t]{5}{*}{ W-B } & Influent(source) & 17.73 & 3.21 & 0.49 & 0.50 & $1.47 \pm 0.06$ & 0.07 & 6.00 & 10.0 & nd & 3.27 & $2.96 \pm 0.13$ & 0.21 \\
\hline & Coagulation and Sedimentation & 2.76 & 3.76 & 0.43 & 0.31 & $0.06 \pm 0.06$ & 0.08 & 1.21 & 3.92 & nd & 0.23 & $1.00 \pm 0.02$ & 0.08 \\
\hline & Influent & 0.88 & 3.31 & 0.49 & 0.19 & $0.02 \pm 0.04$ & 0.07 & 0.02 & 3.01 & nd & 0.16 & $0.22 \pm 0.04$ & 0.06 \\
\hline & Sand Filtration & 0.02 & 2.11 & 0.41 & 0.15 & $0.05 \pm 0.04$ & 0.04 & 0.02 & 3.37 & nd & nd & $0.26 \pm 0.02$ & 0.07 \\
\hline & Finished Water & 0.17 & 2.59 & nd & nd & $0.02 \pm 0.03$ & 0.05 & nd & 8.00 & nd & nd & $0.20 \pm 0.01$ & 0.17 \\
\hline
\end{tabular}

Table 4. The estrogenicity (EEQs, mean \pm deviation) and the concentration of the four selected phenolic estrogens (ng/L). nd: cannot be detected, below LOD.

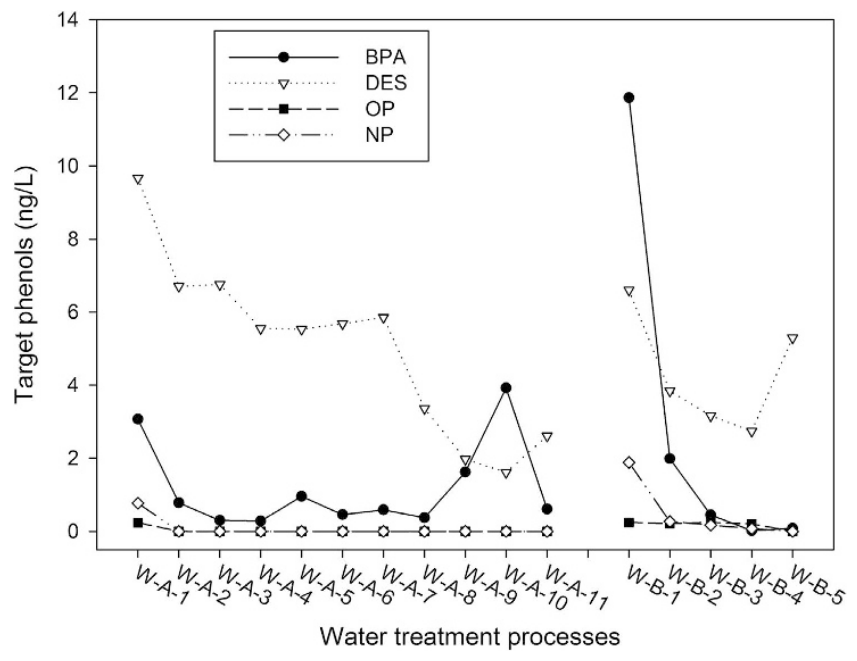

Figure 2. The occurrences of the selected compounds in the water treatment processes. W-A-1: Influent (source); W-A-2: Pre-Oxidation; W-A-3: Biodegradation; W-A-4: Chlorination; W-A-5: Influent; W-A-6: Coagulation and Sedimentation; W-A-7: Sand Filtration; W-A-8: Ozonation; W-A-9: Activated Carbon filtration; W-A-10: Membrane Filtration; W-A-11: Finished Water. W-B-1: Influent(source); W-B-2: Coagulation and Sedimentation; W-B-3: Influent; W-B-4: Sand Filtration; W-B-5: Finished Water.

contribute to the deviations. Significantly higher values obtained in the YES indicated that there were estrogenic compounds in the samples, which were not detected by the chemical target analysis. Reports on the estrogenic activities of surface water pointed out that the steroid estrogens were another group of chemicals that contribute to the estrogenicities ${ }^{43-47}$ and Korner, W. et al. ${ }^{48}$ suggested that E2 and EE2 were the major contributing substances to estrogenic activity in water samples. Anti-estrogenic activities could be the reason for the lower EEQs measured with the YES. This comparison underlines the difficulties in achieving consistent results from biological and chemical analysis, especially in the case of complex environmental samples.

The contributions of the four phenols to the whole sample estrogenic activities were determined as follow: the $\mathrm{EEQs}_{(\mathrm{chem})}$ of each phenol divided the sum of $\mathrm{EEQs}_{(\mathrm{chem})}$ of the four. The contribution ratio to the estrogenic activities induced by the four target phenolic compounds were: DES (99.06\%), followed by NP (0.62\%), OP (0.23\%) and BPA $(0.09 \%)$; therefore, DES was the mainly contributor to the estrogenicity induced by the four phenols.

Removal efficiencies of phenolic EDCs in conventional and advanced water treatment processes. The main goal of this work was to provide important insight into the technology that can most 


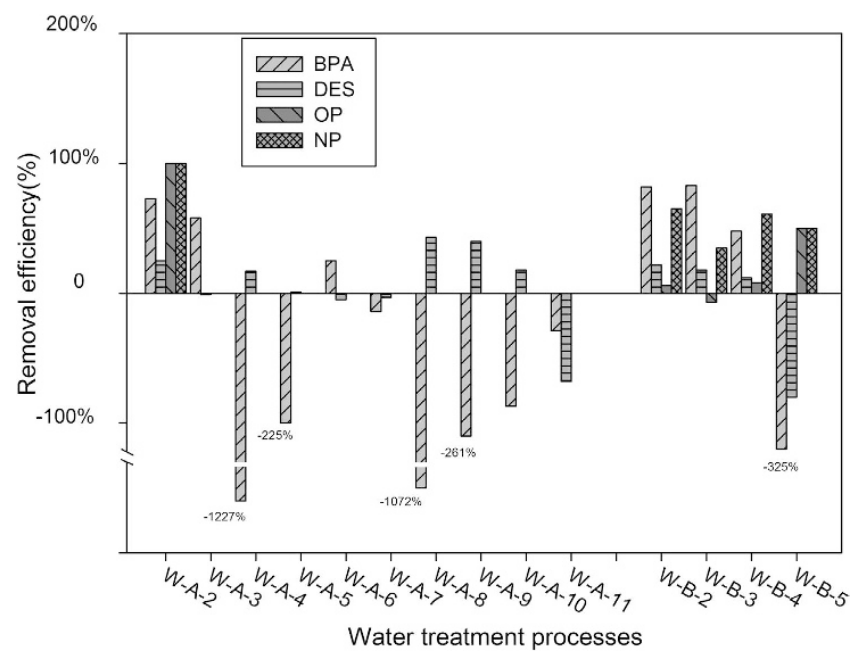

Figure 3. The occurrences of the selected compounds in the water treatment processes. W-A-2: PreOxidation; W-A-3: Biodegradation; W-A-4: Chlorination; W-A-5: Influent; W-A-6: Coagulation and Sedimentation; W-A-7: Sand Filtration; W-A-8: Ozonation; W-A-9: Activated Carbon filtration; W-A-10: Membrane Filtration; W-A-11: Finished Water. W-B-2: Coagulation and Sedimentation; W-B-3: Influent; W-B4: Sand Filtration; W-B-5: Finished Water. Use 0 to replace nd when calculating. The removal efficiency of each process is calculated as follows: $\left(\mathrm{C}_{0}-\mathrm{C}_{1}\right) / \mathrm{C}_{0} \times 100 \% \mathrm{C}_{0}$ : the concentration of the target compounds of process ${ }_{0}$ $\mathrm{C}_{1}$ : the concentration of the target compounds of process ${ }_{1}$ (the process following process ${ }_{0}$ ).

effectively remove phenolic EDCs in the water treatment. The removal efficiencies in each process of the two waterworks were individually analyzed in this study (Fig. 3), as described below.

Total removal efficiencies of each waterworks were also calculated as the concentration of finished water compared to the raw water; the results were: Waterworks A: BPA: $83.34 \%$, DES $64.36 \%$, NP100\%, OP $100 \%$. Waterworks B: BPA: $99.52 \%$, DES: $13.45 \%$, NP100\%, OP $100 \%$.

Removal of BPA. Though BPA is the weakest estrogen among the four selected phenolic compounds according to the EEF values (Table 2) and BPA contributed least according to the contribution ratio, both the two waterworks showed good efficiencies (W-A 83\% and W-B 99\%) in removing BPA from the total treatment processes. The conventional treatment processes (coagulation, sedimentation and sand filtration) present high removal efficiencies, after these treatments, BPA was reduced to the detection limit in some processes, which is in accordance with the researches ${ }^{49,50}$. Also the pre-oxidation and biodegradation in advanced processes were remarkable in removing BPA with the efficiency $73 \%$ and $58 \%$, just like the study pointed out ${ }^{51}$. However, after the membrane filtration step in waterworks A, the concentration of BPA increased (Table 3), considering the application of BPA as a plasticizer in the plastic manufacturing, the leaching of BPA from the ultrafiltration membrane may be the cause $^{52}$. From our study, both conventional and advanced water treatment processes can effectively reduce the concentration of BPA despite the concentration may be increased in some intermediate processes. The removal efficiencies in Fig. 3 like $-1227 \%,-225 \%$ and $-1072 \%$ etc., these values indicating the increasing of BPA and because of the relative low concentration in the former process, the values were much higher when the concentration increased a little.

Removal of DES. Although limited studies focus on the DES in water, DES presents relative high estrogenic activity as the EEF is the highest among the four phenolic compounds, and Jin et al. pointed that DES presented a high risk in source water ${ }^{12}$. In this study, DES presented the highest concentration and the highest contribution ratio, so the people whose drinking water source from the lake are at high risk. The high dose of DES presented in the drinking water may be caused by the drug abuse, for DES was synthetic and used in estrogen replacement therapy. W-A applying the advanced water treatment shows a good removal with the total efficiency $64 \%$, while $\mathrm{W}-\mathrm{B}$, the conventional treatment processes is not so efficient as the efficiency $13 \%$. Through all the conventional treatment technologies, the removal efficiencies are all around $20 \%$, while the advanced ones shows a much higher ratio as the pre-oxidation, ozonation, activated carbon filtration and membrane filtration presented the efficiencies over $20 \%$ even above $40 \%$. The advanced oxidation processes like pre-oxidation and ozonation that can effectively reduce the concentration of DES may due to the chemical characteristic that DES is easily to be oxidized. As presented in our study, advanced treatment processes show a more remarkable removal than the conventional ones.

Removal of OP and NP. Chen et al. reported that oxidation plays an important role in the degradation of NP in water treatment processes ${ }^{49}$. As presented in our study, the pre-oxidation can remarkably reduce the concentration of OP and NP with both the efficiencies are $100 \%$, indicating that oxidation may be a good way to control EDCs in the water ${ }^{21}$. However, both the two waterworks can effectively reduce the concentration of OP 
and NP to below detection, meaning conventional treatment processes were capable in controlling OP and NP levels in finished water even without oxidation.

All these target four phenolic compounds (BPA, DES, NP and OP) tend to bond with suspended particles due to their high $\mathrm{K}_{\mathrm{ow}}$ values and can thus be partially removed by coagulation, sedimentation and sand filtration, just in accordance to many researches ${ }^{21,49,53}$ and as shown in this study, these processes can also remove the estrogens to different extend. It is known that phenolic groups can be oxidized by strong oxidizers, so pollutants containing them, as it is the case of phenolic estrogens, can undergo transformation during chlorination and ozonation ${ }^{54,55}$, and in our study the oxidation processes showed satisfied removal efficiencies. The biodegradation process is another important part of the advanced water treatment processes as it is the process by which microbial organisms transform or alter (through metabolic or enzymatic action) the structure of chemicals introduced into the environment ${ }^{56}$, just as presented in this study, the biodegradation process can effectively reduce BPA.

Overall removal capacity of the conventional and advanced treatment processes. As mentioned above, the total treatment removal efficiency manifested that the conventional and advanced treatment processes can effectively reduce the concentration of BPA, NP and OP with the removal efficiencies were above $80 \%$ even to $100 \%$. However, regarding the case of DES, advanced treatment processes showed much higher reducing ratio to the conventional processes (64.36\% to $13.45 \%)$; generally speaking, the advanced oxidation processes like pre-oxidation and ozonation can remarkably reduce the contaminants. Thus considering the pollution situations of the drinking water source, the advanced treatment processes is recommended.

\section{Conclusion}

In this study, YES assay showed that the estrogenic activities decreased along the processes in both conventional and advanced treatment processes, and the LC-MS/MS analysis found out that BPA, DES and NP were identified in most of the samples, and DES was identified to be the main contributor to the estrogenicity among the four target compounds. From the observation of treatment efficiencies, both conventional and advanced treatment processes can effectively reduce the concentration of BPA, OP and NP, while the advanced ones presented much higher removal ratio in reducing DES. The biodegradation plays an important role in removing BPA and ozonation and pre-oxidation show an effective removal on BPA, DES, OP and NP. Thus a conclusion can be drawn that the advanced water treatment processes were more effective in removing the four phenolic compounds. However, it should be noted that treatment efficiency with low level of chemicals cannot be justified properly, because its concentrations were close to the detection limit. Finally, more specific study seems to be necessary to further understand the mechanisms of the fate and transport of EDCs (phenols, steroids and phthalates) during both conventional and advanced treatment processes.

\section{References}

1. Snyder, S. A., Westerhoff, P., Yoon, Y. \& Sedlak, D. L. Pharmaceuticals, personal care products, and endocrine disruptors in water: Implications for the water industry. Environ. Eng. Sci. 20, 449-469 (2003).

2. Crisp, T. M. et al. Environmental endocrine disruption: an effects assessment and analysis. Environ. Health Perspect. 106, 11-56 (1998).

3. Metzler, M. \& Pfeiffer, E. Chemistry of natural and anthropogenic endocrine active compoundsIn, Metzler, M. (Ed.), Endocrine Disruptors, Part I. The Handbook of Environmental Chemistry, 63-80 (Springer-Verlag, 2001).

4. Zgheib, S., Moilleron, R. \& Chebbo, G. Priority pollutants in urban stormwater: Part 1 - Case of separate storm sewers. Water Res. 46, 6683-6692.

5. Ahel, M., Giger, W. \& Koch, M. Behaviour of alkylphenol polyethoxylate surfactants in the aquatic environment-I. Occurrence and transformation in sewage treatment. Water Res. 28, 1131-1142 (1994).

6. Staples, C. A., Dorn, P. B., Klecka, G. M., O’Block, S. T. \& Harris, L. R. A review of the environmental fate, effects, and exposures of bisphenol A. Chemosphere 36, 2149-2173 (1998).

7. Ying, G.-G., Kookana, R. S. \& Ru, Y.-J. Occurrence and fate of hormone steroids in the environment. Environ. Int. 28, 545-551 (2002).

8. Ying, G.-G., Williams, B. \& Kookana, R. Environmental fate of alkylphenols and alkylphenol ethoxylates-a review. Environ. Int. 28, 215-226 (2002)

9. Pothitou, P. \& Voutsa, D. Endocrine disrupting compounds in municipal and industrial wastewater treatment plants in Northern Greece. Chemosphere 73, 1716-1723 (2008).

10. Zhao, J.-L. et al. Determination of phenolic endocrine disrupting chemicals and acidic pharmaceuticals in surface water of the Pearl Rivers in South China by gas chromatography-negative chemical ionization-mass spectrometry. Sci. Total Environ. 407, 962-974 (2009).

11. Vega-Morales, T., Sosa-Ferrera, Z. \& Santana-Rodríguez, J. J. Determination of alkylphenol polyethoxylates, bisphenol-A, $17 \alpha$-ethynylestradiol and $17 \beta$-estradiol and its metabolites in sewage samples by SPE and LC/MS/MS. J. Hazard. Mater. 183, 701-711 (2010)

12. Jin, S., Yang, F., Xu, Y., Dai, H. \& Liu, W. Risk assessment of xenoestrogens in a typical domestic sewage-holding lake in China. Chemosphere 93, 892-898 (2013).

13. Latini, G. et al. Endocrine Disruptors and Human Health. Mini-Rev. Med. Chem. 10, 846-855 (2010).

14. Casals-Casas, C. \& Desvergne, B. Endocrine disruptors: from endocrine to metabolic disruption. Annu. Rev. Physiol. 73, 135-162 (2011).

15. Frye, C. A. et al. Endocrine disrupters: a review of some sources, effects, and mechanisms of actions on behaviour and neuroendocrine systems. J. Neuroendocrinol. 24, 144-159 (2012).

16. Carlsen, E., Giwercman, A., Keiding, N. \& Skakkebaek, N. E. Declining semen quality and increasing incidence of testicular cancer: is there a common cause? Environ. Health Perspect. 103, Suppl 7, 137-139 (1995).

17. Daston, G. P. et al. Environmental estrogens and reproductive health: A discussion of the human and environmental data. Reprod. Toxicol. 11, 465-481 (1997).

18. Wang, L. et al. Monitoring of selected estrogenic compounds and estrogenic activity in surface water and sediment of the Yellow River in China using combined chemical and biological tools. Environ. Pollut. 165, 241-249 (2012).

19. Wang, L. et al. Assessing estrogenic activity in surface water and sediment of the Liao River system in northeast China using combined chemical and biological tools. Environ. Pollut. 159, 148-156 (2011). 
20. Jiang, W. et al. Assessment of source water contamination by estrogenic disrupting compounds in China. J. Environ. Sci. 24, 320-328 (2012).

21. Pereira, R. O., Postigo, C., de Alda, M. L., Daniel, L. A. \& Barceló, D. Removal of estrogens through water disinfection processes and formation of by-products. Chemosphere 82, 789-799 (2011).

22. Pessoa, G. P. et al. Occurrence and removal of estrogens in Brazilian wastewater treatment plants. Sci. Total Environ. 490, 288-295 (2014).

23. Zhong, W. et al. Screening level ecological risk assessment for phenols in surface water of the Taihu Lake. Chemosphere 80, 998-1005 (2010).

24. Jia, A. et al. In vitro bioassays to evaluate complex chemical mixtures in recycled water. Water Res. 80, 1-11 (2015).

25. Tao, J. et al. Comparison of the Estrogenic Activity of Organic Compounds in Source Water and Finished Water from the Yangtze River and Taihu Lake in Certain Areas of Jiangsu Province. Environ. Sci.(China) 34, 6 (2013).

26. Routledge, E. J. \& Sumpter, J. P. Estrogenic activity of surfactants and some of their degradation products assessed using a recombinant yeast screen. Environ. Toxicol. Chem. 15, 241-248 (1996).

27. Rastall, A. C. et al. The identification of readily bioavailable pollutants in Lake Shkodra/Skadar using semipermeable membrane devices (SPMDs), bioassays and chemical analysis. Environ. Sci. Pollut. Res. 11, 240-253 (2004).

28. Wölz, J. et al. Estrogen receptor mediated activity in bankside groundwater, with flood suspended particulate matter and floodplain soil - An approach combining tracer substance, bioassay and target analysis. Chemosphere 85, 717-723 (2011).

29. Tan, B. L. L. et al. Comprehensive study of endocrine disrupting compounds using grab and passive sampling at selected wastewater treatment plants in South East Queensland, Australia. Environ. Int. 33, 654-669 (2007).

30. Hollert, H. et al. Endocrine disruption of water and sediment extracts in a non-radioactive dot blot/RNAse protection-assay using isolated hepatocytes of rainbow trout. Environ. Sci. Pollut. Res. Int. 12, 347-360 (2005).

31. Beck, I.-C., Bruhn, R. \& Gandrass, J. Analysis of estrogenic activity in coastal surface waters of the Baltic Sea using the yeast estrogen screen. Chemosphere 63, 1870-1878 (2006).

32. Bicchi, C. et al. Analysis of environmental endocrine disrupting chemicals using the E-screen method and stir bar sorptive extraction in wastewater treatment plant effluents. Sci. Total Environ. 407, 1842-1851 (2009).

33. Thorpe, K. L., Gross-Sorokin, M., Johnson, I., Brighty, G. \& Tyler, C. R. An assessment of the model of concentration addition for predicting the estrogenic activity of chemical mixtures in wastewater treatment works effluents. Environ. Health Perspect. 114 Suppl $1,90-97$ (2006).

34. Hoekstra, P. F., Burnison, B. K., Neheli, T. \& Muir, D. C. G. Enantiomer-specific activity of o,p'-DDT with the human estrogen receptor. Toxicol. Lett. 125, 75-81 (2001).

35. Nakada, N. et al. Identification of estrogenic compounds in wastewater effluent. Environ. Toxicol. Chem. 23, 2807-2815 (2004).

36. Shen, J. H., Gutendorf, B., Vahl, H. H., Shen, L. \& Westendorf, J. Toxicological profile of pollutants in surface water from an area in Taihu Lake, Yangtze Delta. Toxicology 166, 71-78 (2001).

37. Cargouët, M., Perdiz, D., Mouatassim-Souali, A., Tamisier-Karolak, S. \& Levi, Y. Assessment of river contamination by estrogenic compounds in Paris area (France). Sci. Total Environ. 324, 55-66 (2004).

38. Vermeirssen, E. L. M. et al. Characterization of the estrogenicity of Swiss midland rivers using a recombinant yeast bioassay and plasma vitellogenin concentrations in feral male brown trout. Environ. Toxicol. Chem. 24, 2226-2233 (2005).

39. Hashimoto, S. et al. Horizontal and Vertical Distribution of Estrogenic Activities in Sediments and Waters from Tokyo Bay, Japan. Arch. Environ. Contam. Toxicol. 48, 209-216 (2005).

40. State Bureau of Standards. Standards for drinking water quality in National Standard of the People's Republic of China, Vol. GB 5749-2006 (China Standards Press, 2007).

41. European Commission, Priority Substances and Certain Other Pollutants according to Annex II of Directive 2008/105/EC. Water Framework Directive (2008) Available at: http://ec.europa.eu/environment/water/water-framework/priority_substances.htm. (Accessed: 18th December 2015)

42. Christiansen, S., Axelstad, M., Boberg, J. \& Hass, U. Low dose effects of BPA on early sexual development of male and female rats. Reprod. Toxicol. 41, 11 (2013).

43. Ra, J. S. et al. Occurrence of estrogenic chemicals in South Korean surface waters and municipal wastewaters. J. Environ. Monit. 13, 101-109 (2011).

44. Rao, K., Lei, B., Li, N., Ma, M. \& Wang, Z. Determination of estrogens and estrogenic activities in water from three rivers in Tianjin, China. J. Environ. Sci. 25, 1164-1171 (2013).

45. Duong, C. N. et al. Estrogenic chemicals and estrogenicity in river waters of South Korea and seven Asian countries. Chemosphere 78, 286-293 (2010)

46. Shi, J., Liu, X., Chen, Q. \& Zhang, H. Spatial and seasonal distributions of estrogens and bisphenol A in the Yangtze River Estuary and the adjacent East China Sea. Chemosphere 111, 336-343 (2014).

47. Snyder, S. A., Villeneuve, D. L., Snyder, E. M. \& Giesy, J. P. Identification and Quantification of Estrogen Receptor Agonists in Wastewater Effluents. Environ. Sci. Technol. 35, 3620-3625 (2001).

48. Korner, W. et al. Substances with estrogenic activity in effluents of sewage treatment plants in southwestern Germany. 2. Biological analysis. Environ. Toxicol. Chem. 20, 2142-2151 (2001).

49. Chen, H. W. et al. Occurrence and assessment of treatment efficiency of nonylphenol, octylphenol and bisphenol-A in drinking water in Taiwan. Sci. Total Environ. 449, 20-28 (2013).

50. Rodriguez-Mozaz, S., López de Alda, M. J. \& Barceló, D. Monitoring of estrogens, pesticides and bisphenol A in natural waters and drinking water treatment plants by solid-phase extraction-liquid chromatography-mass spectrometry. J. Chromatogr. A 1045, $85-92$ (2004).

51. Robinson, B. J. \& Hellou, J. Biodegradation of endocrine disrupting compounds in harbour seawater and sediments. Sci. Total Environ. 407, 5713-5718 (2009).

52. Choi, Y. S., Cho, S., Lee, C., Luu, H. M.-D. \& Guo, J. Contamination of ultrapure water with bisphenol A leached from polysulfone ultrafilter. Talanta 94, 353-355 (2012).

53. Nie, M. et al. Environmental estrogens in a drinking water reservoir area in Shanghai: Occurrence, colloidal contribution and risk assessment. Sci. Total Environ. 487, 785-791 (2014).

54. Alum, A., Yoon, Y., Westerhoff, P. \& Abbaszadegan, M. Oxidation of bisphenol A, 17ß-estradiol, and 17 $\alpha$-ethynyl estradiol and byproduct estrogenicity. Environ. Toxicol. 19, 257-264 (2004).

55. Irmak, S., Erbatur, O. \& Akgerman, A. Degradation of $17 \beta$-estradiol and bisphenol A in aqueous medium by using ozone and ozone/ UV techniques. J. Hazard. Mater. 126, 54-62 (2005).

56. Silva, C. P., Otero, M. \& Esteves, V. Processes for the elimination of estrogenic steroid hormones from water: A review. Environ. Pollut. 165, 38-58 (2012).

\section{Acknowledgements}

This study was supported by funds provided by the National Science and Technology Major Project of the Ministry of Science and Technology of China and Research Project No. 2012ZX07403-001B, and R\&D 
Special Fund for Public Welfare Industry (Health) (201302004).We are also particularly grateful to the WUXI WATERWORKS Co., LTD for their assistance in the experimental work.

\section{Author Contributions}

Conceived and designed the experiments: F.T. Performed the experiments: X.L., S.X. and G.Z. Analyzed the data: X.L. Contributed reagents/materials/analysis tools: X.L., S.X., G.Z., P.J. and F.T. Wrote the paper: X.L. All authors reviewed the manuscript.

\section{Additional Information}

Competing financial interests: The authors declare no competing financial interests.

How to cite this article: Lv, X. et al. Occurrence and removal of phenolic endocrine disrupting chemicals in the water treatment processes. Sci. Rep. 6, 22860; doi: 10.1038/srep22860 (2016).

(c) (i) This work is licensed under a Creative Commons Attribution 4.0 International License. The images or other third party material in this article are included in the article's Creative Commons license, unless indicated otherwise in the credit line; if the material is not included under the Creative Commons license, users will need to obtain permission from the license holder to reproduce the material. To view a copy of this license, visit http://creativecommons.org/licenses/by/4.0/ 